\title{
Tilt table testing in neurology and clinical neurophysiology
}

\author{
D.P. Saal ${ }^{a, *}$, R.D. Thijs ${ }^{a, b}$, J.G. van Dijk ${ }^{a}$ \\ ${ }^{a}$ Dept. of Neurology E Clinical Neurophysiology, Leiden University Medical Centre, Leiden, The Netherlands \\ ${ }^{\mathrm{b}}$ Epilepsy Institute in the Netherlands (SEIN), Heemstede, The Netherlands
}

\section{A R T I C L E I N F O}

\section{Article history:}

Accepted 23 July 2015

Available online $\mathrm{xxxx}$

\section{Keywords:}

Syncope

Reflex syncope

Orthostatic hypotension

Tilt table test

Head-up tilt

\section{H I G H L I G H T S}

- Tilt table testing helps to differentiate the forms of transient loss of consciousness (TLOC) and of syncope.

- Tilt table testing adds to history taking, and cannot be used as its substitution.

- Neurologists and clinical neurophysiologists can play an important role diagnosing syncope or other forms of TLOC, given their experience with extensive history taking.

\section{A B S T R A C T}

Reflex syncope is responsible for 1-6\% of hospital admissions and the economic burden of syncope is huge. A considerable part of these high costs is still spent on tests that are not indicated. Till now few neurologists have taken an interest in syncope and tilt table testing (TTT). However, reflex syncope and epilepsy are often in each other's differential diagnosis and require a similar emphasis on history taking and deductive reasoning. A TTT can be helpful for diagnosis and treatment. The pathophysiological rationale behind the TTT is the fact that it uses gravity to provoke a downwards shift of blood that in turn triggers syncope. Various indications and methods of the TTT are discussed in this paper.

(c) 2015 International Federation of Clinical Neurophysiology. Published by Elsevier Ireland Ltd. All rights reserved.

\section{Contents}

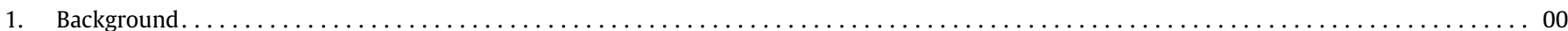

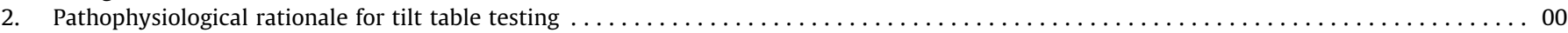

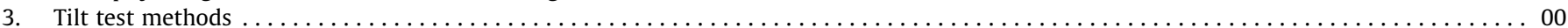

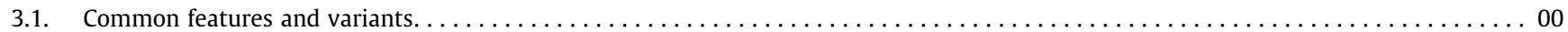

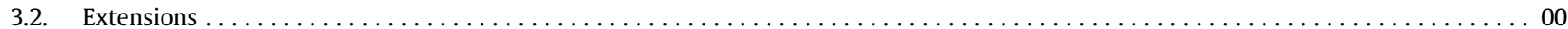

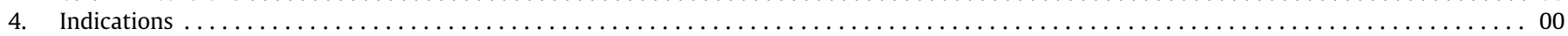

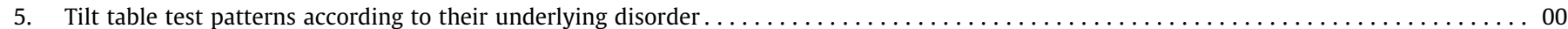

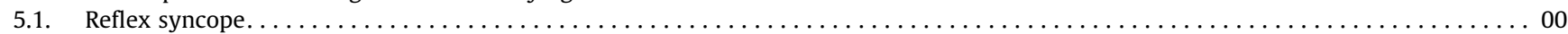

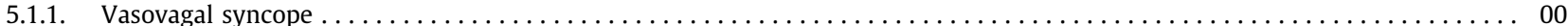

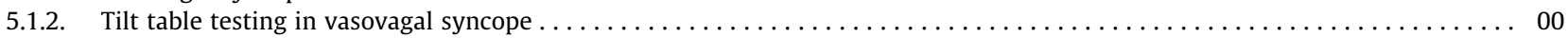

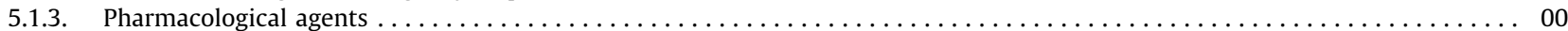

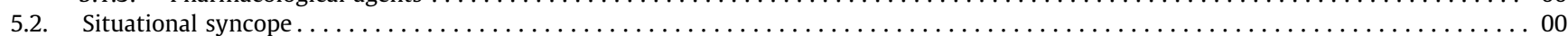

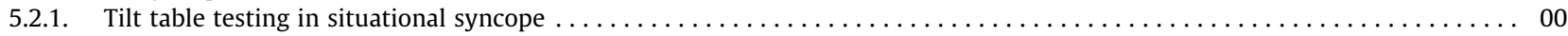

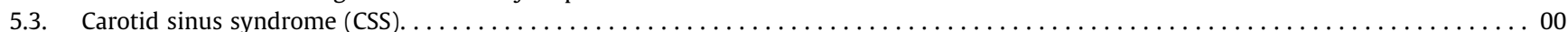

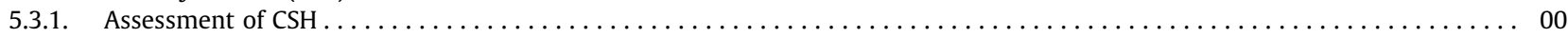

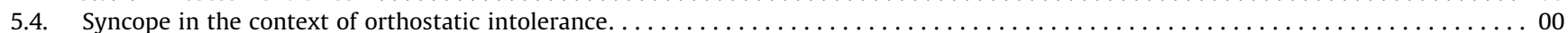

* Corresponding author at: Department of Neurology and Clinical Neurophysiology, Leiden University Medical Centre, Albinusdreef 2, 2300 RC Leiden, The Netherlands. Tel.: +31 71 5266524; fax: +31 715264466 .

E-mail address: d.p.saal@lumc.nl (D.P. Saal). 


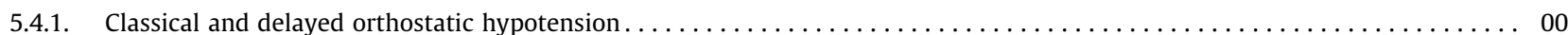

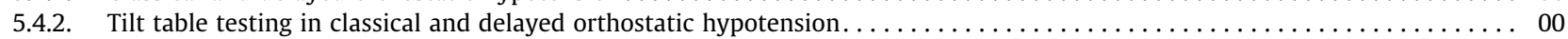

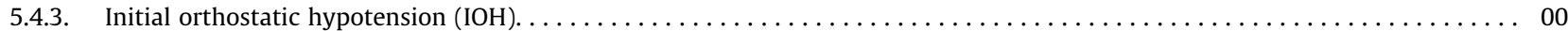

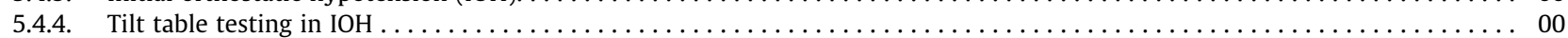

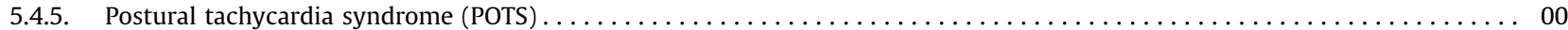

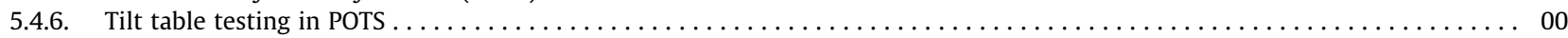

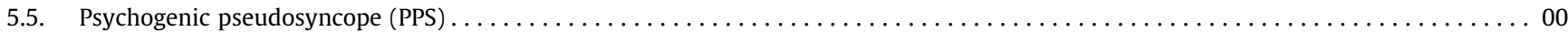

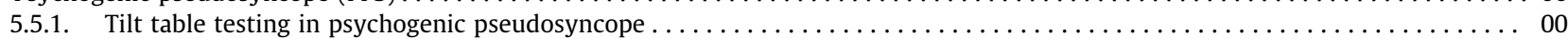

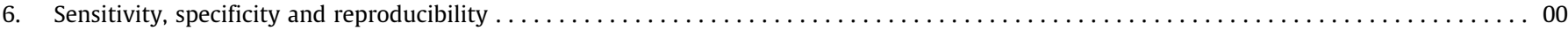

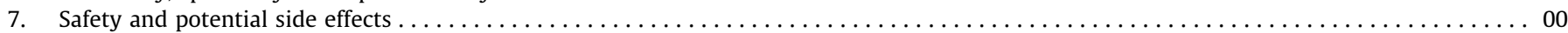

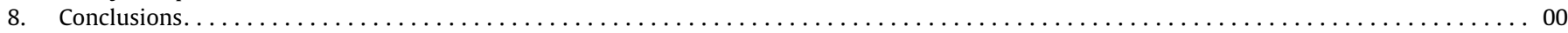

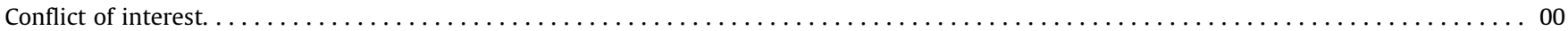

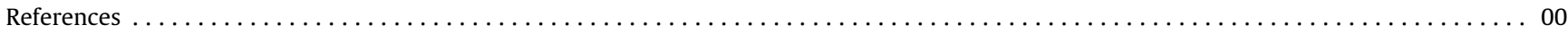

\section{Background}

Syncope and its mimics pose many diagnostic difficulties, caused in part because terms may be used loosely and because not everyone uses a standardised and understandable scheme for classification and terminology. We advocate using the scheme from the most authoritative syncope guideline, the one from the European Society of Cardiology (ESC) (Moya et al., 2009).

In that scheme, transient loss of consciousness (TLOC) is defined as unconsciousness of short duration and spontaneous recovery (Moya et al., 2009; van Dijk et al., 2009; Saal and van Dijk, 2014). The main TLOC forms are syncope, epileptic seizures and episodes of psychogenic apparent unconsciousness (Fig. 1). Syncope is defined as TLOC due to cerebral hypoperfusion (Moya et al., 2009). There are three major groups of causes of syncope: reflex syncope, syncope due to orthostatic hypotension and cardiac syncope (ESC 2009). Reflex syncope, also known as neurally mediated syncope, affects about one third of all people (Ganzeboom et al.,
2006). It is divided into vasovagal syncope, mainly evoked by emotions, pain and standing, situational syncope and carotid sinus syncope.

Reflex syncope is worldwide responsible for $1-6 \%$ of hospital admissions and a frequent reason for referral to internists, cardiologists and neurologists (Brignole et al., 2001). The economic burden of syncope is huge: annual admission costs for syncope were estimated to be about US\$2.4 billion dollar in the USA, comparable to those of asthma and HIV (Sun et al., 2005). A considerable part of these high costs may be spent on admissions and tests that are not necessary according to the ESC guidelines on syncope (Brignole et al., 2006; Kenny et al., 2002; McCarthy et al., 2010; Moya et al., 2009). The underlying reason for this inefficient management strategy is probably that syncope forms a 'blind spot' in medicine. Reflex syncope is not claimed by any speciality and hence not taught in detail. The resulting limited training and expertise with reflex syncope prompts specialists, faced with such patients, to order diagnostic tests for disorders

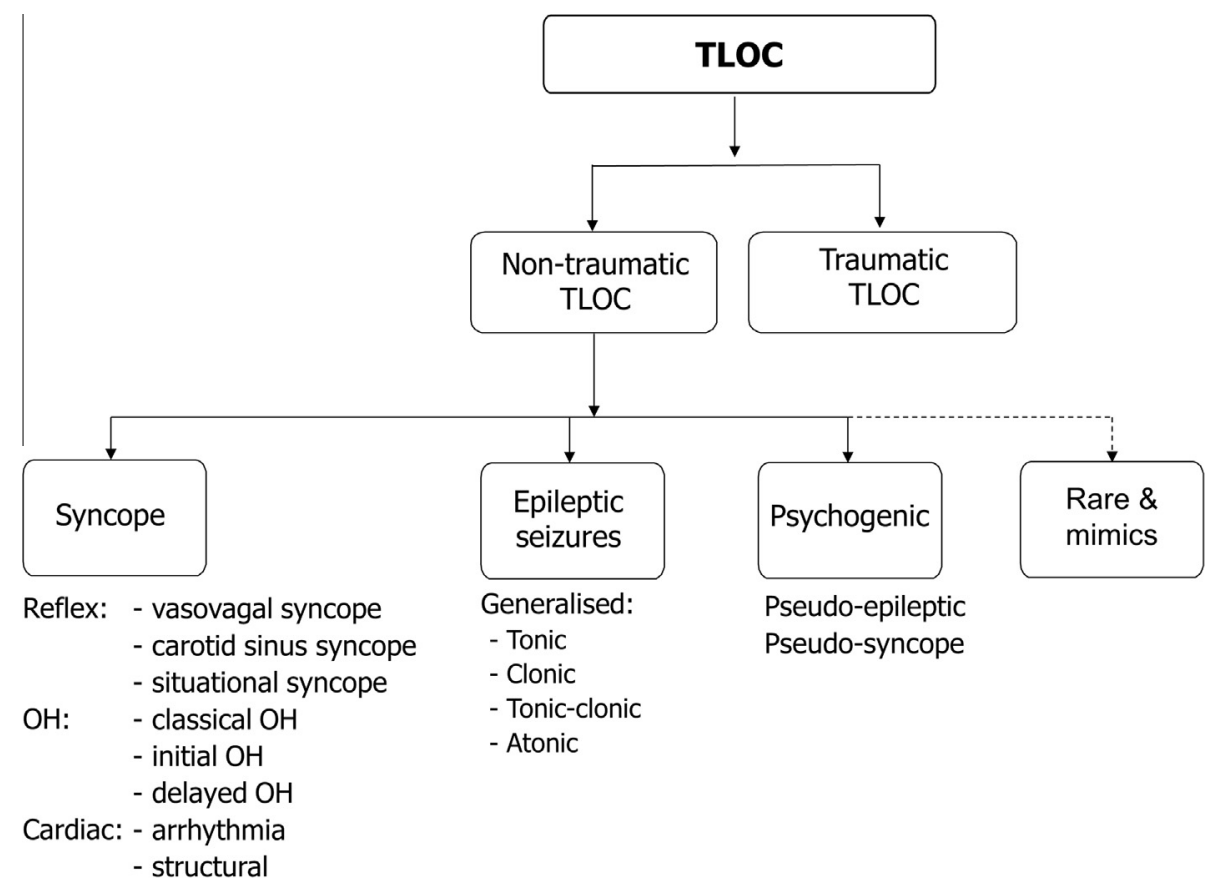

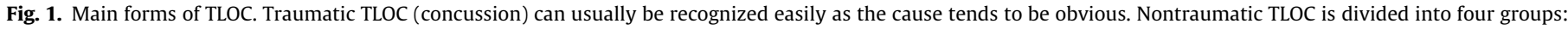

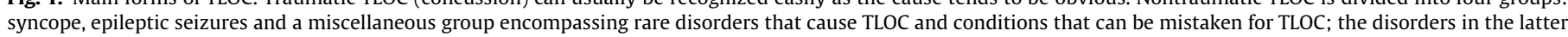
group do not share a common pathophysiology. (TLOC = transient loss of consciousness; OH = orthostatic hypotension) (van Dijk et al., 2009). 
they are familiar with. Neurologists will try to prove or exclude epilepsy and order MRIs and EEGs, while cardiologists aim to exclude structural heart disease or arrhythmia. More knowledge of reflex syncope would suggest a different diagnostic strategy, i. e., appropriate history taking and tests including tilt table testing.

Until recently few neurologists took an active interest in syncope, which is surprising as syncope and epilepsy often feature in one another's differential diagnosis. A clinical interest in syncope may prove beneficial to neurologists, if only to prevent misdiagnosis. Likewise, neurophysiological departments may benefit from adding the TTT to their diagnostic repertoire. The aim of this paper is to review the usefulness of the tilt table test in diagnosing TLOC and associated disorders of orthostatic intolerance, i.e., postural orthostatic tachycardia syndrome (Freeman et al., 2011).

\section{Pathophysiological rationale for tilt table testing}

Tilt table tests were initially used to study physiological compensatory responses to orthostatic stress. In the middle of the 20th century air force investigators recognized the ability of tilt-table tests to induce syncope in a population of pilots (Sheldon, 2005). Tilt table testing was first used as a clinical test by Kenny et al. (1986) who observed a high rate of tilt-induced syncope in patients with previously unexplained syncope.

The rationale for the tilt table test can be best understood through the physiology of standing. When one stands up from the supine position, gravity will cause blood to be transferred from the thoracic cavity to the lower limbs (Smit et al., 1999; van Dijk and Wieling, 2013). Normally, 500-1000 ml of blood shifts from the upper to the lower body. Approximately $80 \%$ of the blood pooled in the lower limb is contained in the thighs (Ludbrook, 1966). Excessive pooling is prevented by neurovascular and neurohumoral mechanisms, aided by the mechanical forces of the 'muscle pump' in the legs. Standing up immediately increases

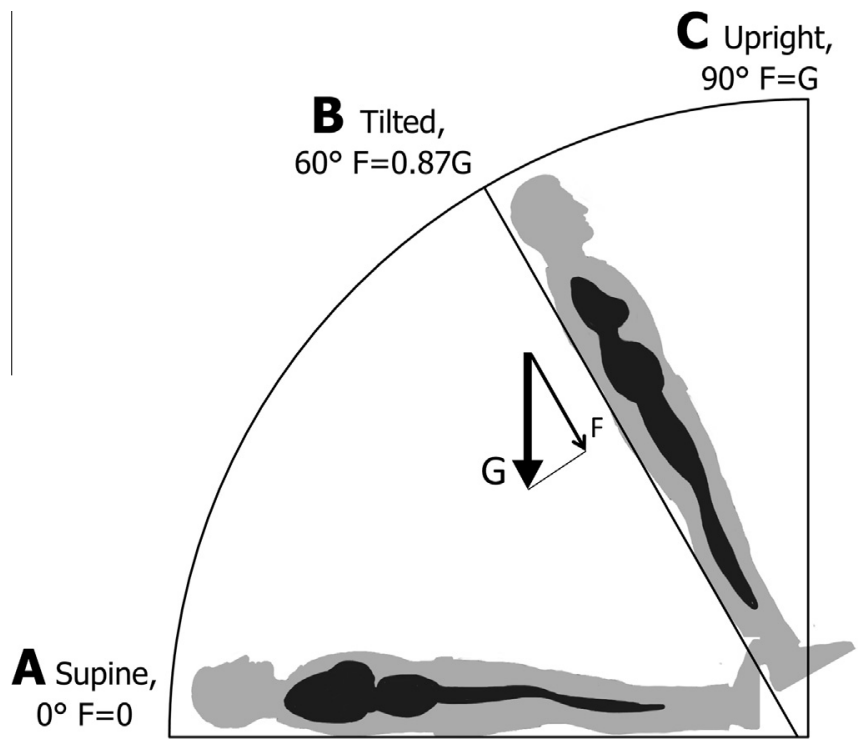

Fig. 2. Scheme of tilt table test. In situation $A$, a person is shown in the supine position, i.e., a tilt angle of $0^{\circ}$. The black shape represents the blood volume, with relatively much blood in the thorax. The gravity force $G$ always acts vertically down. It has a component $F$ pulling blood in the direction of the feet, equalling the sine of the tilt angle. A tilt angle of $60^{\circ}$ (B) results in $F=0.87 \mathrm{G}$. The pull of blood towards the feet results in a change in the distribution of blood, as shown. The force $F$ would be maximal at a tilt angle of $90^{\circ}(\mathrm{C})$, but a potential fall in this position is more threatening than in a tilted position. Angles of $60^{\circ}(F=0.87 \mathrm{G})$ or $70^{\circ}(F=0.94 \mathrm{G})$ are less threatening while providing adequate forces displacing blood towards the feet. heart rate, resulting from central mechanisms related to the initiation of the postural change together with deactivation of the baroreceptors. These so-called 'stretch receptors' are found in the walls of the carotid sinus and the aorta. These baroreceptors sense the drop in blood pressure caused by a downwards shift of blood and decreased venous return. The deactivation of the baroreceptors has several reflex effects: vagal outflow to the sinus node decreases which increases heart rate, and sympathetic vasoconstriction is augmented which increases blood pressure. Furthermore, it induces neurohumoral changes including a release of vasopressin (Hasser et al., 1997; Wieling et al., 2008). The orthostatic heart rate response is characterised by a primary peak within $3 \mathrm{~s}$, increasing further to a second peak around $12 \mathrm{~s}$. This increase is more gradual and mainly due to further reflex inhibition of cardiac vagal tone together with an augmented sympathetic outflow to the sinus node. Once the increase of vasomotor tone has successfully counteracted the drop in arterial blood pressure, baroreflexmediated mechanisms will result in a subsequent relative heart rate decrease, resulting in a steady state of blood pressure and heart rate about $30 \mathrm{~s}$ after standing up; heart rate increases by $15-30 \%$. The net increase of BP upon standing is explained by the height difference between the baroreceptors and the heart (Wieling et al., 2008).

Reflex syncope can be triggered by gradual pooling of blood in the thighs, buttocks, pelvis and the splanchnic circulation. The pooled blood is situated in the distensible venous capacitance system, probably mainly in the splanchnic vascular bed (Stewart et al., 2004). The result of this pooling is a decrease in venous return (van Lieshout et al., 1997; Freeman, 2006; Sandhu et al., 2013). It is not completely known how excessive pooling triggers the vasovagal reflex. 'Central hypovolemia', i.e., reduced filling of the heart and the thoracic great vessels probably plays an important role in triggering the reflex. For an overview of the various causes of syncope and their symptoms see ESC 2009 (Moya et al., 2009; van Dijk et al., 2009; Wieling et al., 2009). TTT provokes pooling and may hereby induce reflex syncope. Interestingly, TTT not only provokes syncope in those in whom fainting is induced by standing, but also in those with emotional triggers for syncope.

\section{Tilt test methods}

\subsection{Common features and variants}

Several methods for tilt table testing have been developed, with or without pharmacological challenges. The test should be performed in a quiet room. Blood pressure can change dramatically in seconds in syncope and should be measured at a high temporal resolution. Conventional sphygmomanometric measurements at best allow measurements every minute, inadequate for syncope assessment. Several commercial devices offer finger photoplethysmography, which relies on a cuff around a finger. The pressure in the cuff is constantly adapted to the pressure in the finger, resulting in a fully continuous measurement of blood pressure, $i$. e., beat-to-beat, as well as heart rate (Imholz et al., 1998). Another advantage is that additional software may allow additional circulatory parameters to be calculated, such as cardiac output and total peripheral resistance, which allow a detailed circulatory analysis. At least one ECG lead is required to detect bradycardia or asystole.

The angle of the table should be between $60^{\circ}$ and $80^{\circ}$ (Fig. 2) (Fitzpatrick et al., 1991). The reason for such angles instead of a fully vertical position is that they hardly diminish the gravity effect, while allowing subjects to relax. An additional effect of tilting to $60-80^{\circ}$ may be that it prevents leg muscle action, which abolishes the leg muscle pump (Wieling et al., 2008; Borst et al., 1982). The subject should be protected against falling by using 


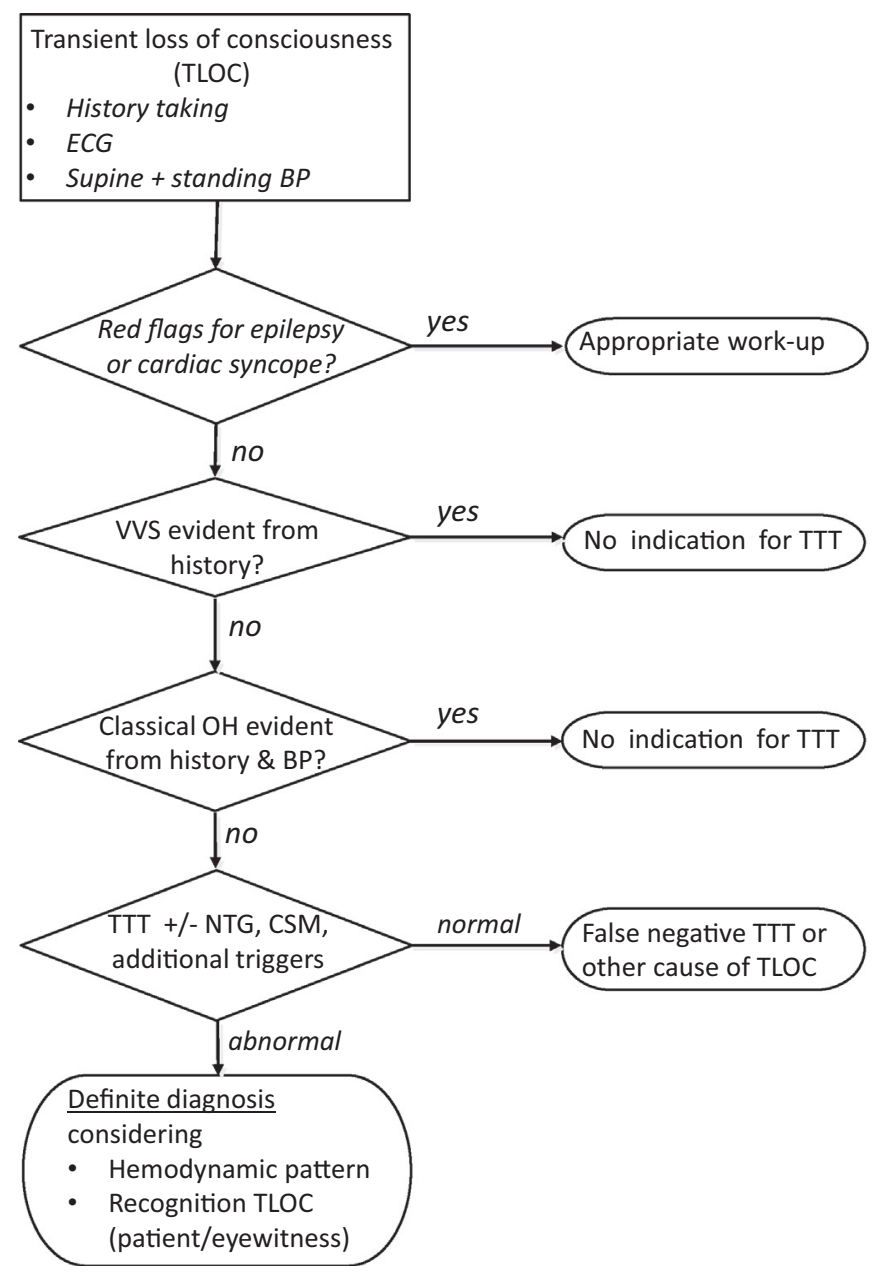

Fig. 3. Diagnostic flowchart for patients with transient loss of consciousness (TLOC). First check for red flags for epilepsy and cardiac syncope (see ESC guidelines, 2009: Tables 11 and 13). If VVS or classical $\mathrm{OH}$ is evident from history a TTT is not necessary. In other cases a TTT should be performed. The execution of the TTT depends on the clinical suspicion from history taking. In case of an abnormal TTT the hemodynamic pattern together with the recognition by the patient or the eyewitness of the spontaneous attack facilitates a definite diagnosis. TTT patterns are discussed separately in section 5 for each diagnosis. VVS: vasovagal syncope, TTT: tilt table test, $\mathrm{OH}$ : orthostatic hypotension, BP: blood pressure, NTG: nitroglycerin, CSM: carotid sinus massage.

\section{Table 1}

Indications and methods for tilt table testing. TTT, tilt table testing; NTG, nitroglycerine; CSM, carotid sinus massage; VVS, vasovagal syncope; CSS, carotid sinus syndrome; $\mathrm{OH}$, orthostatic hypotension; POTS, postural tachycardia syndrome; PPS, psychogenic pseudosyncope.

\begin{tabular}{llllll}
\hline & $\begin{array}{l}\text { TTT } \\
\text { (passive) }\end{array}$ & $\begin{array}{l}\text { NTG (after 20 min } \\
\text { passive phase) }\end{array}$ & $\begin{array}{l}\text { Additional } \\
\text { provocation }\end{array}$ & $\begin{array}{l}\text { Active } \\
\text { standing }\end{array}$ & CSM \\
\hline \multicolumn{2}{l}{ Reflex syncope } & & & & - \\
VVS & + & + & & - & - \\
CSS & + & + & Triggers & - & - \\
Situational & + & + & & & \\
OH & & & + & - \\
Classical & + & - & ++ & - \\
Initial & ++ & - & & \\
POTS & + & + & & \\
PPS & + & + & & \\
Cardiac syncope & No TTT & & \\
\hline
\end{tabular}

safety straps. The duration of the test varies, but the available evidence suggests that $30-45 \mathrm{~min}$ is optimal. Patients should be tilted back when pronounced hypotension or bradycardia and presyn- cope ensues (Sheldon, 2013), although some prefer to provoke complete syncope. The ESC-guideline recommends a duration of 40 min (Moya et al., 2009). Additional pharmacological challenges will be discussed later.

\subsection{Extensions}

The use of a video-EEG recording during tilt table testing is recommended because it helps to differentiate syncope from epileptic seizures or psychogenic pseudosyncope (LaRoche et al., 2011). EEG machines allow all signals to be recorded simultaneously, offering the added advantage that all records can be studied after the test, allowing a detailed analysis of semiology (van Dijk et al., 2014). The addition of EEG to TTT allows a further check on proceedings in that the onset of slowing of the EEG should always result in tilting the patient back, or in reverse that tilting back is not yet obligatory if the EEG is still normal. Furthermore, the EEG, slow or with flattening, provides additional information about the degree of cerebral perfusion (van Dijk et al., 2014). The diagnostic yield of the TTT can be further enhanced with the use of carotid sinus massage (CSM), particularly in those with history of unexplained syncope or falls and a negative history for cardiovascular diseases (Blanc, 2013). In some centres lower body negative pressure is used as an additional method to trigger reflex syncope (Lelorier et al., 2003).

A key element of the test is to ask the patient for recognition of complaints. Eyewitnesses may help confirm whether the provoked event resembled the spontaneous episodes, which helps to reduce false positive results. Transcranial doppler (TCD) monitoring during TTT also helps to assess alterations in cerebral blood flow. This is of particular interest to investigate the pathophysiology of syncope, but has so far not been shown to be of diagnostic value.

\section{Indications}

The European Society of Cardiology (Moya et al., 2009) recommends the use of tilt testing when the initial examination of syncope, consisting of history taking, ECG and supine plus standing blood pressure measurements, has not yielded a diagnosis. The aim of the TTT is to provoke a typical event, to obtain a clinicalpathophysiological correlate and thus prove the cause of TLOC. Apart from syncope, TTT has been advocated in the elderly with unexplained falls (Heitterachi et al., 2002). Fig. 3 shows a pragmatic approach, beginning with the initial analysis of history taking, ECG and orthostatic blood pressure measurements (ESC 2009). If this results in obvious reflex syncope, a TTT is not necessary; the same holds if orthostatic hypotension explains the

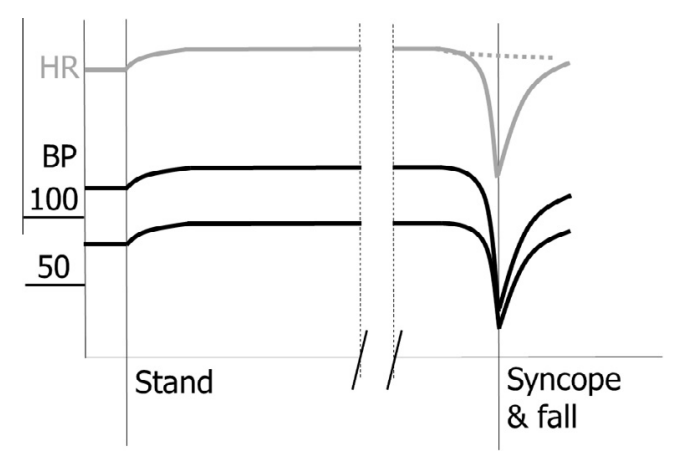

Fig. 4a. Circulatory patterns in vasovagal syncope. Schematic blood pressure and heart rate patterns for vasovagal syncope evoked by standing. In both vasodepressor and cardioinhibitory vasovagal syncope, a fall in blood pressure signifies the onset of the reflex (van Dijk et al., 2009). 


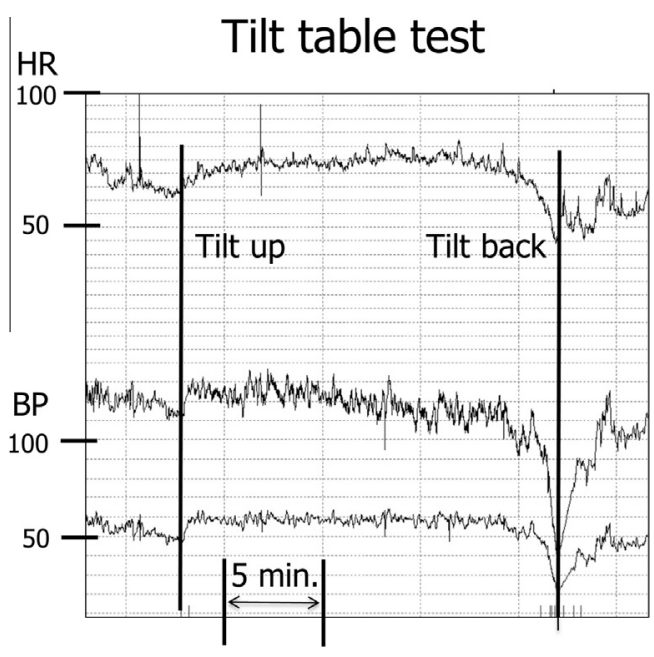

Fig. 4b. Circulatory patterns in TTT in a case of vasovagal syncope. HR; heart rate BP; blood pressure (top: systolic BP, bottom: diastolic BP).

clinical problem fully. Hence, TTT is useful when syncope is likely but its cause is unclear. TTT is also useful to diagnose psychogenic pseudo syncope and POTS. In the next section we will discuss these disorders along with the specific patterns they exhibit during tilt table testing (Table 1 ).

\section{Tilt table test patterns according to their underlying disorder}

\subsection{Reflex syncope}

Reflex syncope, also called 'neurally mediated syncope', is characterised by a sudden decrease in blood pressure and/or slowing of heart rate. This is in contrast with syncope due to neurogenic orthostatic hypotension $(\mathrm{OH})$ where a progressive fall in BP with little or no decrease in HR are the main characteristics. In syncope due to non-neurogenic $\mathrm{OH}$ there is a progressive fall in $\mathrm{OH}$ with significant increase in HR. (Freeman et al., 2011; van Dijk and Wieling, 2013).

Reflex syncope consists of three subgroups: vasovagal, situational and carotid sinus syncope. The afferent pathways of reflex syncope are largely unknown. Reflex syncope is typically preceded by specific prodromal symptoms and signs (pallor, nausea, diaphoresis, abdominal discomfort, including an urge to void or defaecate and at times even causing explosive diarrhoea), that may occur up to $60 \mathrm{~s}$ or more prior to the loss of consciousness. (van Dijk et al., 2009; Moya et al., 2009; Wieling et al., 2009) This 'autonomic activation' is not a direct effect of cerebral hypoperfusion, but is a marker of the underlying cause of the syncope (Wieling et al., 2009).

\subsubsection{Vasovagal syncope}

Vasovagal syncope is triggered most often by pain, fear or prolonged standing. It is characterised by autonomic activation before and sometimes after the event. These warning signs may be systematically absent in the elderly (Kenny and Traynor, 1991). The factors triggering the vasovagal cascade can be divided into central emotional influences and peripheral circulatory ones, the latter in the form of pooling of blood. The contribution of reduced vasoconstriction in the minutes before a faint to the events culminating in syncope has been criticised recently (Verheyden et al., 2008; Raj, 2008). Systemic vascular resistance decreases in only about one half of subjects before vasovagal syncope (Fuca et al., 2006). A decrease in cardiac output was however a consistent finding in all subjects prior to syncope. Regardless of how vasovagal syncope is triggered, the events during syncope are clear: blood pressure always decreases and heart rate may do so, but not always.

\subsubsection{Tilt table testing in vasovagal syncope}

Reflex syncope and in particular vasovagal syncope is the most common indication for a tilt table test. The test starts with a resting phase in which patients are kept supine for $10 \mathrm{~min}$, followed by a 'passive phase', in which the table is tilted head up between 60 and $80^{\circ}$ for $20 \mathrm{~min}$. When this does not provoke typical complaints, it is followed in many laboratories by administering a pharmacological agent.

Blood pressure and heart rate during tilt table testing in vasovagal syncope can show three different patterns: vasodepressive, mixed and cardioinhibitory. (Brignole et al., 2000; Sutton et al., 1992). The vasodepressive pattern consists of a fall in blood pressure falls while heart rate shows little or no decrease (Figs. 4a and 4b). In this form heart rate should not fall more than $10 \%$ from its peak value and the fall in blood pressure precipitates syncope (Sutton et al., 1992). The cardioinhibitory pattern consists of pronounced bradycardia (ventricular rate $\leqslant 40$ ) or asystole $(>3 \mathrm{~s})$ as the main cause of syncope (Sutton et al., 2000). The most common pattern is the 'mixed' one, in which the drop in blood pressure is followed by bradycardia (Moya et al., 2009). The three different patterns can be distinguished with a TTT. Surprisingly, the TTT has a therapeutic effect in some cases: the recurrence rate of syncope is lower after a positive tilt table test (Sheldon et al., 1996). This is possibly due to a better recognition of warning symptoms, allowing patients to take adequate preventive measures. The occurrence of a recognised event during TTT helps convince patients of the certainty of the diagnosis. The TTT can be expanded by teaching patients physical counter-manoeuvres while offering them visual feedback of the circulatory effects using finger photoplethysmography (Wieling et al., 2004).

\subsubsection{Pharmacological agents}

Pharmacological provocation during head-up tilt testing helps to increase the diagnostic yield. Prior to the actual syncope in tilt-induced syncope, adrenomedullary activity is higher in individuals susceptible to fainting compared with controls (Sra et al., 1994), which prompted the idea of administering catecholamines to patients suspected of suffering from vasovagal syncope. The use of isoproterenol raised sensitivity from $50 \%$ to $80 \%$ at the cost of a fall in specificity in high dose regimens (Carlioz et al., 1997; Parry and Kenny, 1999). Other centres used nitrates as a provocative agent (Raviele et al., 1995; Ungar et al., 2013; Brignole et al., 2004) Nitrates have a vasodilatory effect, with marked effects on the venous bed, which promotes the syncopal cascade through the peripheral route by increased venous pooling and a decrease in venous return. Nitrates they can be given sublingually, e.g., a spray of 400 micrograms of nitroglycerin, or intravenously; the latter approach has the advantage of a rapid onset of action and a relatively constant plasma concentration (Aerts, 2003), but injection may provoke syncope by itself. The sublingual administration is easy and safe to administer. Sensitivity ranges from $51 \%$ to $81 \%$ and specificity from $85 \%$ to $94 \%$ (Parry and Kenny, 1999). Another drug used is clomipramine: it enhances serotonergic activity by inhibiting 5-hydroxytryptamine (5-HT) and has a central serotonergic response (Theodorakis et al., 1998). Some authors (Furukawa et al., 2011) showed that the use of clomipramine during TTT preferentially induced a cardioinhibitory response while nitroglycerin promoted a vasodepressor response.

\subsection{Situational syncope}

Situational syncope is reflex syncope provoked by other triggers than those seen in vasovagal and carotid sinus syncope, such as 


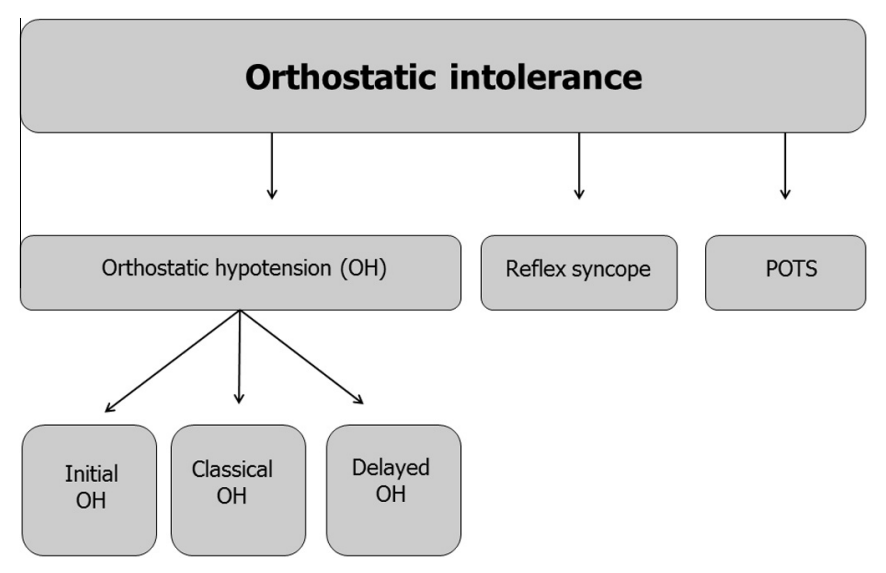

Fig. 5. Different forms of orthostatic intolerance. Note that orthostatic intolerance may be explained by reflex syncope, i.e., orthostatic vasovagal syncope. $\mathrm{OH}$; orthostatic hypotension, POTS; postural tachycardia syndrome.

miction, defecation, coughing, sneezing, laughing, stretching. They share the efferent pathway common to all forms of reflex syncope but differ in afferent pathways (Benditt, 1997).

\subsubsection{Tilt table testing in situational syncope}

The test protocol in situational syncope is the same as in vasovagal syncope, as patients with situational syncope are often susceptible to an orthostatic challenge. Still, the positive rate in passive tilting in situational syncope has been stated to be lower than that for VVS (in one example 6\% vs. 27\%) (Livanis et al., 2004). It can be useful to provoke an event by having the patient reproduce his or her specific trigger, such as coughing or stretching.

\subsection{Carotid sinus syndrome (CSS)}

Carotid sinus hypersensitivity (CSH) denotes an overly strong circulatory response to massage of the carotid sinus. Syncope related to CSH consists of two forms. Spontaneous CSS is a reflex syncope occurring mostly in the elderly, in which syncope is caused by external pressure on the neck, as can happen during shaving. Note that this spontaneous form is rare. The term CSS is also used for otherwise unexplained syncope in the elderly who have CSH. The ESC guidelines (Moya et al., 2009) advocate to perform CSM in every patient with syncope over 40 years in whom no diagnosis was established after the initial evaluation (Blanc, 2013).

\subsubsection{Assessment of CSH}

The test is performed in supine and repeated after tilting upwards. The carotid arteries are sequentially massaged for 7-10 s (Blanc, 2013). CSH is present when one of two signs appear: asystole for more than $3 \mathrm{~s}$, or a decrease in systolic blood pressure of more than $50 \mathrm{mmHg}$ (or an absolute systolic blood pressure lower than $80 \mathrm{mmHg}$ ). The response to the test may be cardioinhibitory, vasodepressive or mixed. Some authors found these criteria overly sensitive (Krediet et al., 2011) and proposed a more stringent cut-off in the form of an asystole $(\geqslant 3 \mathrm{~s}$ ) or a fall in mean arterial pressure below $60 \mathrm{mmHg}$ lasting for $\geqslant 6 \mathrm{~s}$. The incidence of transient neurological complications during CSM is low (0.1\%). Because of the risk of neurological complications it should be avoided in patients with a transient ischaemic attack, stroke or myocardial infarction in the last three months (Munro et al., 1994; Moya et al., 2009), but these considerations are not evidence-based.

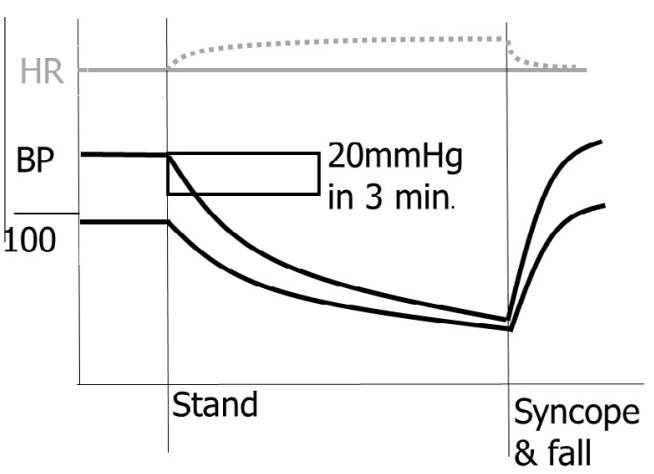

Fig. 6a. Circulatory patterns in syncope due to orthostatic hypotension, similar to Fig. 3. Note that blood pressure drops immediately after standing up and that the rate of drop decreases (van Dijk et al., 2009).

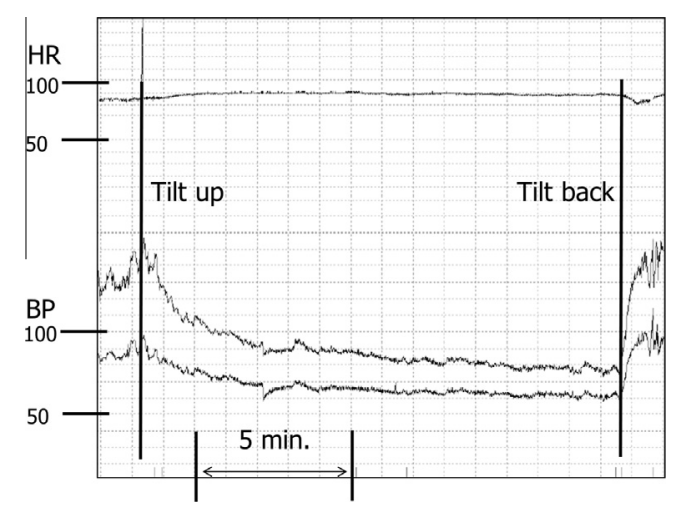

Fig. 6b. Circulatory patterns due to orthostatic hypotension in real life: similar to Fig. 3b.

\subsection{Syncope in the context of orthostatic intolerance}

The classification used in this paper (Fig. 1) is built around transient loss of consciousness (Fig. 1), but TTT can also be useful in disorders causing 'orthostatic intolerance' (OI), in which consciousness is not necessarily lost. OI refers to a range of symptoms evoked by the upright position due to an imbalance in circulatory control. Syncope is one; others are light-headedness, dizziness, weakness, sweating and palpitations (Freeman et al., 2011). Common causes of OI are reflex syncope, orthostatic hypotension and postural orthostatic tachycardia syndrome (POTS) (Wieling et al., 2007) (Fig. 5). The classifications of TLOC and OI overlap partially because the various disorders differ in their tendency to cause OI or syncope. OI can develop very quickly, for instance in vasovagal syncope, but may also develop over many minutes, as can be seen in neurogenic $\mathrm{OH}$. The duration of OI can likewise vary from seconds as in asystolic vasovagal syncope to many hours, such as in POTS.

\subsubsection{Classical and delayed orthostatic hypotension}

5.4.1.1. Classical $\mathrm{OH}$. In classical orthostatic hypotension standing provokes hypotension through an impairment of sympathetic function resulting in insufficient vasoconstriction, in turn leading to venous pooling. Alternatively a similar response may result from hypovolemia, e.g., in people with a severe gastrointestinal bleeding. The pattern of changes in blood pressure and heart rate differ fundamentally from those in reflex syncope: whereas blood pressure and heart rate decrease with increasing speed in reflex syncope, the decreases in orthostatic hypotension start quickly after which the rate of change decreases. This may be likened to 


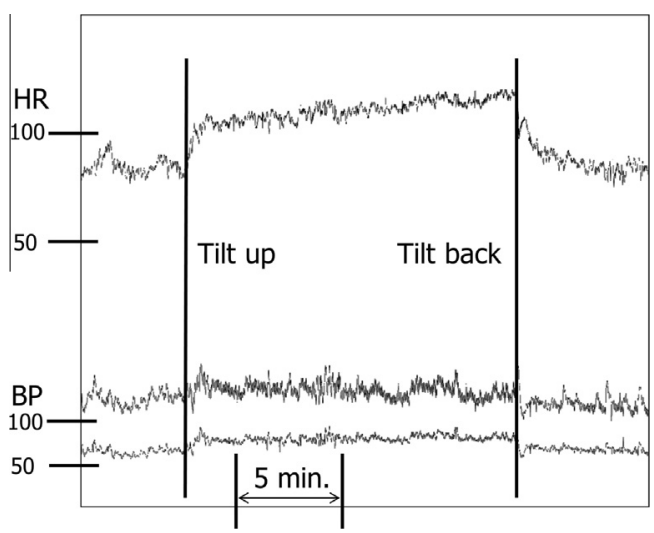

Fig. 7. Postural orthostatic tachycardia syndrome. Note the change in heart rate (HR) from 70 beats/minute to over 110 beats/minute.

a leak in a balloon, in which the initial high pressure ensures a quick leak and the later lower pressure a slow one. Note that classical $\mathrm{OH}$ is due to failure of a normal reflex, while reflex syncope concerns an abnormal reflex action. Classical $\mathrm{OH}$ can be non-neurogenic and neurogenic. The first form is mostly due to drugs and is very common, especially in the elderly. Neurogenic $\mathrm{OH}$ occurs less often and is often a feature of synucleinopathies (Parkinson's disease, multisystem atrophy and pure autonomic failure) and some rare autoimmune disorders (e.g., acute autonomic ganglionopathy) (Metzler et al., 2013).

Classical $\mathrm{OH}$ is operationally defined as a decrease in systolic blood pressure $(\mathrm{BP})>=20 \mathrm{mmHg}$ or in diastolic $\mathrm{BP}>=10 \mathrm{mmHg}$ within three minutes of standing up or being tilted head up (Freeman et al., 2011). Note that such BP decreases need not be accompanied by complaints. The occurrence of syncope probably does not depend on the magnitude of the BP fall, but on the absolute BP level (Wieling et al., 2009): an $80 \mathrm{mmHg}$ fall from 180 to $100 \mathrm{mmHg}$ will not cause syncope, but a fall from 110 to $30 \mathrm{mmHg}$ will.

5.4.1.2. Delayed $\mathrm{OH}$. Delayed orthostatic hypotension occurs later than 3 min after standing up. It is more common in the elderly and is probably caused by an increased peripheral pooling, increased fluid transudation or gradual failure of humoral and neural mechanisms (Gibbons and Freeman, 2006).

\subsubsection{Tilt table testing in classical and delayed orthostatic hypotension}

As mentioned earlier, in syncope due to orthostatic hypotension blood pressure starts to drop immediately on standing up (van Dijk et al., 2009). To compensate for this decrease heart rate will rise unless there is additional autonomic damage preventing this increase. The rate of the blood pressure falls and tends to stabilize at a low level, unless syncope occurs (Figs. 6a and 6b). As for vasovagal syncope, in case of an established event the physical counter manoeuvres can be taught in the same session with the use of finger photoplethysmography.

\subsubsection{Initial orthostatic hypotension ( $\mathrm{IOH})$}

$\mathrm{IOH}$ results from a mismatch between cardiac output and peripheral vascular resistance when people stand up quickly. An important difference with classical $\mathrm{OH}$ is that the hypotension is transient even in the upright position, so blood pressure will normalise within seconds, while in classical $\mathrm{OH}$ blood pressure will usually only increase again when other actions are taken, such as exercise or sitting down. Groups at risk for IOH are, firstly, young, tall patients with an asthenic habitus (Wieling et al., 2004) and secondly those of any age taking medication interfering with vasoconstrictor mechanisms (Wieling et al., 2007).

\subsubsection{Tilt table testing in $\mathrm{IOH}$}

$\mathrm{IOH}$ only occurs during active standing, not during passive tilting. IOH therefore requires an active standing test (Fedorowski and Melander, 2013).

\subsubsection{Postural tachycardia syndrome (POTS)}

The main characteristic of POTS is a sustained heart rate increment within $10 \mathrm{~min}$ after standing of $\geqslant 30$ beats/minute (in children $\geqslant 40$ beats/minute) (Freeman et al., 2011; Raj, 2013). POTS is associated with OI, chronic fatigue and may be due to a limited autonomic neuropathy. POTS may be preceded by a recent viral illness. The syndrome is more common in young women. The orthostatic symptoms include blurred vision, palpitations, and weakness, especially of the legs. Only a minority of patients faint. In contrast to VVS or $\mathrm{OH}$, the relation between the complaints and the circulatory alterations is not clear.

\subsubsection{Tilt table testing in POTS}

During TTT the heart rate increases on standing while the blood pressure remains unaltered or decreases a little (Fig. 7).

\subsection{Psychogenic pseudosyncope (PPS)}

This condition is psychologically probably very similar in nature to psychogenic non-epileptic seizures (PNES); the only difference between PPS and PNES may be a lack of gross movements in psychogenic pseudosyncope. This difference may still induce a different medical history though, as patients with PNES are likely to be seen by neurologists and may receive anti-epileptic drugs, while those with PPS are seen by those dealing with syncope (Tannemaat et al., 2013). PPS usually has a higher frequency than VVS, sometimes several times a day, and a longer duration of the episodes (Puppala et al., 2014). In contrast to syncope the eyes are almost always closed in PPS (Tannemaat et al., 2013).

\subsubsection{Tilt table testing in psychogenic pseudosyncope}

In patients with PPS the EEG is normal during the event, and blood pressure and heart rate are usually increased during the event (Tannemaat et al., 2013; Petersen et al., 1995). A documented episode during a tilt table test with recognition by the patient or relatives makes the diagnosis certain, which is useful to help patients accept the diagnosis (Shen et al., 1999).

\section{Sensitivity, specificity and reproducibility}

The specificity of tilt table testing is difficult to establish. While vasovagal syncope is essentially a lifelong condition with a lifetime prevalence of 20 to $40 \%$ (Brignole et al., 2001) with a tendency to begin before the age of 35 years (Serletis et al., 2006), the first syncope can occur at any age. This raises two problems (Sheldon, 2005): firstly, how many 'control subjects' are in fact fainters who have not fainted yet, but will do so later? Secondly, if a tilt table test identifies people predisposed to fainting, then a population of young control subjects will result in more abnormal tilt tests than an older population. Moreover, pharmacological agents generally increase sensitivity while reducing specificity (Sheldon, 2003; Shen et al., 1999). The reproducibility of the tilt table test has been debated: long-term reproducibility, varying from 1 day to 4 years, shows reproducible responses in $50-85 \%$ of subjects (Parry and Kenny, 1999; Raviele et al., 1990; Fitzpatrick and Sutton, 1989; Petkar and Fitzpatrick, 2008). The degree of bradycardia and hypotension evoked during several tilt tests are 
only modestly reproducible, which suggests that a classification based on hemodynamic changes during a single tilt test has limited predictive value (Brignole et al., 2001). In fact, it should be understood that tilt table testing does not predict prognosis in syncope (Sheldon et al., 1997).

In view of the above, tilt testing has been criticised both for its diagnostic yield and for problems concerning what it tests. An emerging view is that, in the context of reflex syncope, TTT does not so much test for the presence of a disease as for a susceptibility to reflex hypotension, which may be so widespread in the population that it may well coincide with another condition causing syncope (Sutton and Brignole, 2014). In the authors' view, understanding these aspects of TTT has several consequences. Firstly, tilt testing should never be merely summarised as normal or abnormal, but the result must be stated according to the circulatory pattern found. Secondly, an abnormal result is clinically most meaningful if there was recognition of the event as similar to spontaneous ones, by patients and preferably also by eyewitnesses. Thirdly, the test lends itself well to teaching patients how to perform counter manoeuvres. Patients often report more confidence in dealing with syncope after a tilt table test, which may partially explain why the syncope rate drops after a tilt table test (Sheldon et al., 1996). This may be due to 'expectancy', which, while part of the placebo effect, is beneficial to patients (Sahota et al., 2014). Overall, tilt table testing should be seen as an important addition to history taking, and never as an isolated procedure.

\section{Safety and potential side effects}

As tilt testing is designed to provoke syncope, its safety has been a consideration since its introduction. Baron-Esquivias et al. (2002) found that the long-term survival of patients with asystole did not differ from those without it, which included the elderly. Gieroba et al. (2004) performed tilt table testing in 1096 subjects between 60 and 74 years of age and 873 people aged 75 or older and found only one case of atrial fibrillation during tilt table testing, and no neurological complications. One case was described in which a patient with ischaemic heart disease developed ventricular fibrillation with isoproterenol provocation in (Leman et al., 1999). Hence, a tilt table test is safe and complications are very rare. Still, some cautionary notes are in order: firstly, the low blood pressure during syncope might harm those with ischaemic disorders of the heart or brain, so risks and benefits should be weighed in such patients. Secondly, an association between white matter lesions and frequent syncope, defined as five or more syncopal spells during life, has been described (Kruit et al., 2013). This association does not mean that frequent syncope causes brain damage, but should nevertheless prompt caution in evoking syncope. The authors feel that the advantages of a clear diagnosis, with possibly fewer future syncopal spells as a result, outweigh the possible risk of adding to white matter lesions by one syncopal spell during TTT.

\section{Conclusions}

In summary, a tilt table test helps establish whether episodes of transient loss of consciousness are due to syncope and, if so, yields ictal patterns of blood pressure and heart rate that define the type of syncope. Tilt testing provokes an event in a considerable number of patients, which shortens the delay to a certain diagnosis. Neurologists and clinical neurophysiologists have a potentially important role to play in this regard, but as yet few of them take an active interest in syncope. This is unfortunate as the main strategy in reflex syncope is extensive history taking, so in this way neurologists are well-suited to deal with reflex syncope. We feel that even neurologists who wish to restrict their attention to epilepsy must be thoroughly familiar with reflex syncope, if only to prevent misdiagnosis. It is well known that a misdiagnosis of epilepsy may bring significant clinical, socioeconomic and psychological burden to the patient (Rangel et al., 2014).

The basic skills needed to diagnose syncope are the same as for epilepsy: patients are usually seen well after the event occurred, making history taking and deductive reasoning especially important. These qualities form the neurologist's basic skills, often allowing a diagnosis without additional testing. When tests are necessary, the paths of epilepsy and syncope diverge, as they require different approaches. A tilt table test measures physiological functions of the nervous system, and may be regarded as analogous to the EEG. While tilt table testing can become an important clinical neurophysiological tool for TLOC diagnosis, it should be seen as an important addition to history taking and never as an isolated procedure.

\section{Conflict of interest}

None of the authors have potential conflicts of interest to be disclosed.

\section{References}

Aerts AJ. Nitrate stimulated tilt table testing: a review of the literature. Pacing Clin Electrophysiol 2003;26:1528-37.

Baron-Esquivias G, Pedrote A, Cayuela A, Valle JI, Fernandez JM, Arana E, Fernandez M, Morales F, Burgos J, Martinez-Rubio A. Long-term outcome of patients with asystole induced by head-up tilt test. Eur Heart J 2002;23:483-9.

Benditt DG. Neurally mediated syncopal syndromes: pathophysiological concepts and clinical evaluation. Pacing Clin Electrophysiol 1997;20:572-84.

Blanc JJ. Clinical laboratory testing: what is the role of tilt-table testing, active standing test, carotid massage, electrophysiological testing and ATP test in the syncope evaluation? Prog Cardiovasc Dis 2013;55:418-24.

Borst C, Wieling W, van Brederode JF, Hond A, de Rijk LG, Dunning AJ. Mechanisms of initial heart rate response to postural change. Am J Physiol 1982;243: H676-81.

Brignole M, Alboni P, Benditt D, Bergfeldt L, Blanc JJ, Bloch Thomsen PE, van Dijk JG, Fitzpatrick A, Hohnloser S, Janousek J, Kapoor W, Kenny RA, Kulakowski P, Moya A, Raviele A, Sutton R, Theodorakis G, Wieling W. Guidelines on management (diagnosis and treatment) of syncope. Eur Heart J 2001;22:1256-306.

Brignole M, Alboni P, Benditt DG, Bergfeldt L, Blanc JJ, Bloch Thomsen PE, van Dijk JG, Fitzpatrick A, Hohnloser S, Janousek J, Kapoor W, Kenny RA, Kulakowski P, Masotti G, Moya A, Raviele A, Sutton R, Theodorakis G, Ungar A, Wieling W. Guidelines on management (diagnosis and treatment) of syncope - update 2004. Europace 2004;6:467-537.

Brignole M, Menozzi C, Del RA, Costa S, Gaggioli G, Bottoni N, Bartoli P, Sutton R. New classification of haemodynamics of vasovagal syncope: beyond the VASIS classification. Analysis of the pre-syncopal phase of the tilt test without and with nitroglycerin challenge. Vasovagal Syncope International Study. Europace 2000;2:66-76.

Brignole M, Ungar A, Bartoletti A, Ponassi I, Lagi A, Mussi C, Ribani MA, Tava G, Disertori M, Quartieri F, Alboni P, Raviele A, Ammirati F, Scivales A, De ST Standardized-care pathway vs. usual management of syncope patients presenting as emergencies at general hospitals. Europace 2006:8:644-50.

Carlioz R, Graux P, Haye J, Letourneau T, Guyomar Y, Hubert E, Bodart JC, Lequeuche B, Burlaton JP. Prospective evaluation of high-dose or low-dose isoproterenol upright tilt protocol for unexplained syncope in young adults. Am Heart J 1997; 133:346-52.

Fedorowski A, Melander O. Syndromes of orthostatic intolerance: a hidden danger. Intern Med 2013;273:322-35.

Fitzpatrick A, Sutton R. Tilting towards a diagnosis in recurrent unexplained syncope. Lancet 1989;1:658-60.

Fitzpatrick AP, Theodorakis G, Vardas P, Sutton R. Methodology of head-up tilt testing in patients with unexplained syncope. J Am Coll Cardiol 1991; 17:125-30.

Freeman R. Assessment of cardiovascular autonomic function. Clin Neurophysio 2006; $117: 716-30$.

Freeman R, Wieling W, Axelrod FB, Benditt DG, Benarroch E, Biaggioni I, et al Consensus statement on the definition of orthostatic hypotension, neurally mediated syncope and the postural tachycardia syndrome. Clin Auton Res: Off $J$ Clin Auton Res Soc 2011:21:69-72.

Fuca G, Dinelli M, Suzzani P, Scarfo S, Tassinari F, Alboni P. The venous system is the main determinant of hypotension in patients with vasovagal syncope. Europace 2006;8:839-45

Furukawa T, Maggi R, Solano A, Croci F, Brignole M. Effect of clinical triggers on positive responses to tilt-table testing potentiated with nitroglycerin or clomipramine. Am J Cardiol 2011;107:1693-7. 
Ganzeboom KS, Mairuhu G, Reitsma JB, Linzer M, Wieling W, van DN. Lifetime cumulative incidence of syncope in the general population: a study of 549 Dutch subjects aged 35-60 years. J Cardiovasc Electrophysiol 2006;17:1172-6.

Gibbons CH, Freeman R. Delayed orthostatic hypotension: a frequent cause of orthostatic intolerance. Neurology 2006;67:28-32.

Gieroba ZJ, Newton JL, Parry SW, Norton M, Lawson J, Kenny RA. Unprovoked and glyceryl trinitrate-provoked head-up tilt table test is safe in older people: a review of 10 years' experience. J Am Geriatr Soc 2004;52:1913-5.

Hasser EM, Bishop VS, Hay M. Interactions between vasopressin and baroreflex control of the sympathetic nervous system. Clin Exp Pharmacol Physiol 1997;24:102-8.

Heitterachi E, Lord SR, Meyerkort P, McCloskey I, Fitzpatrick R. Blood pressure changes on upright tilting predict falls in older people. Age Ageing 2002;31:181-6.

Imholz BP, Wieling W, van Montfrans GA, Wesseling KH. Fifteen years experience with finger arterial pressure monitoring: assessment of the technology. Cardiovasc Res 1998;38:605-16.

Kenny RA, Ingram A, Bayliss J, Sutton R. Head-up tilt: a useful test for investigating unexplained syncope. Lancet 1986:1:1352-5.

Kenny RA, O'Shea D, Walker HF. Impact of a dedicated syncope and falls facility for older adults on emergency beds. Age Ageing 2002;31:272-5.

Kenny RA, Traynor G. Carotid sinus syndrome-clinical characteristics in elderly patients. Age Ageing 1991;20:449-54.

Krediet CT, Parry SW, Jardine DL, Benditt DG, Brignole M, Wieling W. The history of diagnosing carotid sinus hypersensitivity: why are the current criteria too sensitive? Europace 2011:13:14-22.

Kruit MC, Thijs RD, Ferrari MD, Launer LJ, van Buchem MA, van Dijk JG. Syncope and orthostatic intolerance increase risk of brain lesions in migraineurs and controls. Neurology 2013;80:1958-65.

LaRoche S, Taylor D, Walter P. Tilt table testing with video EEG monitoring in the evaluation of patients with unexplained loss of consciousness. Clin EEG Neurosci 2011;42:202-5.

Lelorier P, Klein GJ, Krahn A, Yee R, Skanes A, Shoemaker JK. Combined head-up tilt and lower body negative pressure as an experimental model of orthostatic syncope. J Cardiovasc Electrophysiol 2003;14:920-4.

Leman RB, Clarke E, Gillette P. Significant complications can occur with ischemic heart disease and tilt table testing. Pacing Clin Electrophysiol 1999:22:675-7.

Livanis EG, Leftheriotis D, Theodorakis GN, Flevari P, Zarvalis E, Kolokathis F Kremastinos DT. Situational syncope: response to head-up tilt testing and follow-up: comparison with vasovagal syncope. Pacing Clin Electrophysiol 2004;27:918-23.

Ludbrook J. The musculovenous pumps of the human lower limb. Am Heart J 1966;71:635-41.

McCarthy F, De BS, Rice C, McMahon CG, Geary U, Plunkett PK, Crean P, Murphy R, Foley B, Mulvihill N, Kenny RA, Cunningham CJ. Resource utilisation for syncope presenting to an acute hospital Emergency Department. Ir. J. Med. Sci. 2010;179:551-5.

Metzler M, Duerr S, Granata R, Krismer F, Robertson D, Wenning GK. Neurogenic orthostatic hypotension: pathophysiology, evaluation, and management. J Neurol 2013;260:2212-9.

Moya A, Sutton R, Ammirati F, Blanc JJ, Brignole M, Dahm JB, Deharo JC, Gajek J, Gjesdal K, Krahn A, Massin M, Pepi M, Pezawas T, Ruiz GR, Sarasin F, Ungar A, van Dijk JG, Walma EP, Wieling W. Guidelines for the diagnosis and management of syncope (version 2009). Eur Heart J 2009;30:2631-71.

Munro NC, McIntosh S, Lawson J, Morley CA, Sutton R, Kenny RA. Incidence of complications after carotid sinus massage in older patients with syncope. J Am Geriatr Soc 1994;42:1248-51.

Parry SW, Kenny RA. Tilt table testing in the diagnosis of unexplained syncope. QJM 1999;92:623-9.

Petersen ME, Williams TR, Sutton R. Psychogenic syncope diagnosed by prolonged head-up tilt testing. OJM 1995:88:209-13.

Petkar S, Fitzpatrick A. Tilt-table testing: transient loss of consciousness discriminator or epiphenomenon? Europace 2008;10:747-50.

Puppala VK, Dickinson O, Benditt DG. Syncope: classification and risk stratification. J Cardiol 2014:63:171-7.

Raj SR. Is cardiac output the key to vasovagal syncope? A reevaluation of putative pathophysiology. Heart Rhythm 2008;5:1702-3.

Raj SR. Postural tachycardia syndrome (POTS). Circulation 2013;127:2336-42.

Rangel I, Freitas J, Correia AS, Sousa A, Lebreiro A, de SC, Maciel MJ, Azevedo E. The usefulness of the head-up tilt test in patients with suspected epilepsy. Seizure 2014;23:367-70

Raviele A, Gasparini G, Di PF, Delise P, Bonso A, Piccolo E. Usefulness of head-up tilt test in evaluating patients with syncope of unknown origin and negative electrophysiologic study. Am J Cardiol 1990;65:1322-7.

Raviele A, Menozzi C, Brignole M, Gasparini G, Alboni P, Musso G, Lolli G, Oddone D, Dinelli M, Mureddu R. Value of head-up tilt testing potentiated with sublingua nitroglycerin to assess the origin of unexplained syncope. Am J Cardiol 1995;76:267-72.
Saal DP, van Dijk JG. Classifying syncope. Auton Neurosci 2014;184:3-9.

Sahota I, Sheldon R, Pournazari P. Clinical improvement of vasovagal syncope in the absence of specific therapies: the Seinfeld effect. Cardiol J 2014;21:637-42.

Sandhu KS, Khan P, Panting J, Nadar S. Tilt-table test: its role in modern practice. Clin Med 2013:13:227-32.

Serletis A, Rose S, Sheldon AG, Sheldon RS. Vasovagal syncope in medical students and their first-degree relatives. Eur Heart J 2006;27:1965-70.

Sheldon R. Tilt testing for syncope: a reappraisal. Curr Opin Cardiol 2005;20:38-41.

Sheldon R. Tilt table testing and implantable loop recorders for syncope. Cardiol Clin 2013;31:67-74

Sheldon R, Rose S, Flanagan P, Koshman ML, Killam S. Risk factors for syncope recurrence after a positive tilt-table test in patients with syncope. Circulation 1996;93:973-81.

Sheldon R, Rose S, Koshman ML. Comparison of patients with syncope of unknown cause having negative or positive tilt-table tests. Am J Cardiol 1997;80:581-5.

Sheldon R. Initial evaluation of the syncope patient. Part 2: role of defined questionnaire for diagnosis of syncope and other forms of transient loss of consciousness. In: Benditt DG, Blanc JJ, Brignole M, Sutton R, editors. The evaluation and treatment of syncope. A handbook for clinical practice. New York: Futura for Blackwell Publishing; 2003. p. 46-50.

Shen WK, Jahangir A, Beinborn D, Lohse CM, Hodge DO, Rea RF, Hammill SC. Utility of a single-stage isoproterenol tilt table test in adults: a randomized comparison with passive head-up tilt. J Am Coll Cardiol 1999;33:985-90.

Smit AA, Halliwill JR, Low PA, Wieling W. Pathophysiological basis of orthostatic hypotension in autonomic failure. J Physiol 1999;519:1-10.

Sra JS, Murthy V, Natale A, Jazayeri MR, Dhala A, Deshpande S, Sheth M, Akhtar M. Circulatory and catecholamine changes during head-up tilt testing in neurocardiogenic (vasovagal) syncope. Am J Cardiol 1994;73:33-7.

Stewart JM, McLeod KJ, Sanyal S, Herzberg G, Montgomery LD. Relation of postural vasovagal syncope to splanchnic hypervolemia in adolescents. Circulation 2004; $110: 2575-81$

Sun BC, Emond JA, Camargo Jr CA. Direct medical costs of syncope-related hospitalizations in the United States. Am J cardiol 2005;95:668-71.

Sutton R, Petersen M, Brignole M, Raviele A, Menozzi C, Giani P. Proposed classification for tilt induced vasovagal syncope. Eur J Card Pacing Electrophysiol 1992;2:180-3.

Sutton R, Brignole M. Twenty-eight years of research permit reinterpretation of tilttesting: hypotensive susceptibility rather than diagnosis. Eur Heart J 2014;35:2211-2.

Sutton R, Brignole M, Menozzi C, Raviele A, Alboni P, Giani P, Moya A. Dual-chamber pacing in the treatment of neurally mediated tilt-positive cardioinhibitory syncope: pacemaker versus no therapy: a multicenter randomized study. The Vasovagal Syncope International Study (VASIS) Investigators. Circulation 2000;102:294-9.

Tannemaat MR, van NJ, Reijntjes RH, Thijs RD, Sutton R, van Dijk JG. The semiology of tilt-induced psychogenic pseudosyncope. Neurology 2013;81:752-8.

Theodorakis GN, Markianos M, Livanis EG, Zarvalis E, Flevari P, Kremastinos DT. Central serotonergic responsiveness in neurocardiogenic syncope: a clomipramine test challenge. Circulation 1998;98:2724-30.

Ungar A, Sgobino P, Russo V, Vitale E, Sutton R, Melissano D, Beiras X, Bottoni N, Ebert HH, Gulizia M, Jorfida M, Moya A, Andresen D, Grovale N, Brignole M. Diagnosis of neurally mediated syncope at initial evaluation and with tilt table testing compared with that revealed by prolonged ECG monitoring. An analysis from the Third International Study on Syncope of Uncertain Etiology (ISSUE-3). Heart 2013:99:1825-31.

van Dijk JG, Thijs RD, Benditt DG, Wieling W. A guide to disorders causing transient loss of consciousness: focus on syncope. Nat Rev Neurol 2009;5:438-48.

van Dijk JG, Thijs RD, van Zwet E, Tannemaat MR, van Niekerk J, Benditt DG, et al. The semiology of tilt-induced reflex syncope in relation to electroencephalographic changes. Brain: J Neurol 2014;137:576-85.

van Dijk JG, Wieling W. Pathophysiological basis of syncope and neurological conditions that mimic syncope. Prog Cardiovasc Dis 2013;55:345-56.

van Lieshout JJ, Wieling W, Karemaker JM. Neural circulatory control in vasovagal syncope. Pacing Clin Electrophysiol 1997;20:753-63.

Verheyden B, Liu J, van DN, Westerhof BE, Reybrouck T, Aubert AE, Wieling W. Steep fall in cardiac output is main determinant of hypotension during drug-free and nitroglycerine-induced orthostatic vasovagal syncope. Heart Rhythm 2008:5:1695-701.

Wieling W, Ganzeboom KS, Saul JP. Reflex syncope in children and adolescents. Heart 2004;90:1094-100.

Wieling W, Krediet CT, van DN, Linzer M, Tschakovsky ME. Initial orthostatic hypotension: review of a forgotten condition. Clin Sci (Lond) 2007:112:157-65.

Wieling W, Thijs RD, van DN, Wilde AA, Benditt DG, van Dijk JG. Symptoms and signs of syncope: a review of the link between physiology and clinical clues. Brain 2009;132:2630-42. 